\section{$\left[{ }^{90}\right.$ Y]Yttrium Microspheres \\ Radioembolotherapy in Desmoplastic Small Round Cell Tumor Hepatic Metastases}

\section{Case Report}

A 20-year-old otherwise healthy white man presented with a 5-week history of abdominal pain and diarrhea. Investigations for acute viral hepatitis were negative. Over the next month, he developed abdominal distention. Intravenous iodinated contrast-enhanced computed tomography (CT) of the abdomen and pelvis revealed multiple bulky soft tissue intraperitoneal masses and paraesophageal lymphadenopathy. A diagnostic CT-guided biopsy of a lesion in the left upper abdomen was performed. Immunohistochemistry of the specimen was positive for desmin, cytokeratin, FLI1, and BAF47; focally positive for epithelial membrane antigen; and negative for synaptophysin neuron-specific enolase, CD45, CD30, $\alpha$-fetoprotein, human chorionic gonadotropin, and CD56. The tumor was also found to be positive for the EWSR1-WT1 primary fusion transcript, pathognomonic for desmoplastic small round cell tumor (DSRCT).

Systemic chemotherapy with vincristine, doxorubicin, and ifosfamide was initiated. After four cycles, the patient underwent extensive abdominal tumor debulking, which included splenectomy, appendectomy, and removal of multiple peritoneal tumor nodules ranging in size from 0.1 to $6.5 \mathrm{~cm}$. Postoperatively, he received irinotecan for 5 days. One month later, he received irinotecan and temozolomide, completing five cycles over the next 3 months. Two months later, the patient underwent repeat laparotomy with extensive peritoneal nodule resection (116 lesions), lysis of adhesions, porta hepatis and celiac lymphadenectomy, hepatic wedge resection, gastrostomy, and jejunostomy insertion. Concomitantly, he received continuous hyperthermic peritoneal perfusion (CHPP) with cisplatin $100 \mathrm{mg} / \mathrm{m}^{2}$.

After surgery, cyclophosphamide plus vinorelbine was initiated, but after two cycles, the disease was found to have progressed. Restaging $\left[{ }^{18} \mathrm{~F}\right]$ fluorodeoxyglucose $\left(\left[{ }^{18} \mathrm{~F}\right] \mathrm{FDG}\right)$ positron emission tomography (PET) -CT showed $\left[{ }^{18} \mathrm{~F}\right] \mathrm{FDG}$-avid mulitfocal thoracic lymphadenopathy. Extensive intra- and extrahepatic metastases were noted at the porta hepatis, contiguous with the lesser sac. The patient was enrolled onto a phase I study and received cixutumumab (IMC-A12; ImClone Systems, New York, NY), an insulin-like growth factor receptor antibody, in combination with temsirolimus, a mammalian target of rapamycin inhibitor. His participation ended because of the development of obstructive hyperbilirubinemia (total bilirubin, $21.8 \mu \mathrm{mol} / \mathrm{L}$; direct bilirubin, $20.6 \mu \mathrm{mol} / \mathrm{L}$ ) and elevated serum transaminases. He received conformal external beam radiation to the porta hepatis tumor (30 Gy in 10 daily fractions [3 Gy per fraction]) in a successful attempt to alleviate the biliary obstruction. $\left[{ }^{18} \mathrm{~F}\right]$ FDG PET-CT demonstrated metabolic response corresponding to the area associated with metastases of the porta hepatis treated with radiation (Fig 1). However, outside this radiation treatment field,

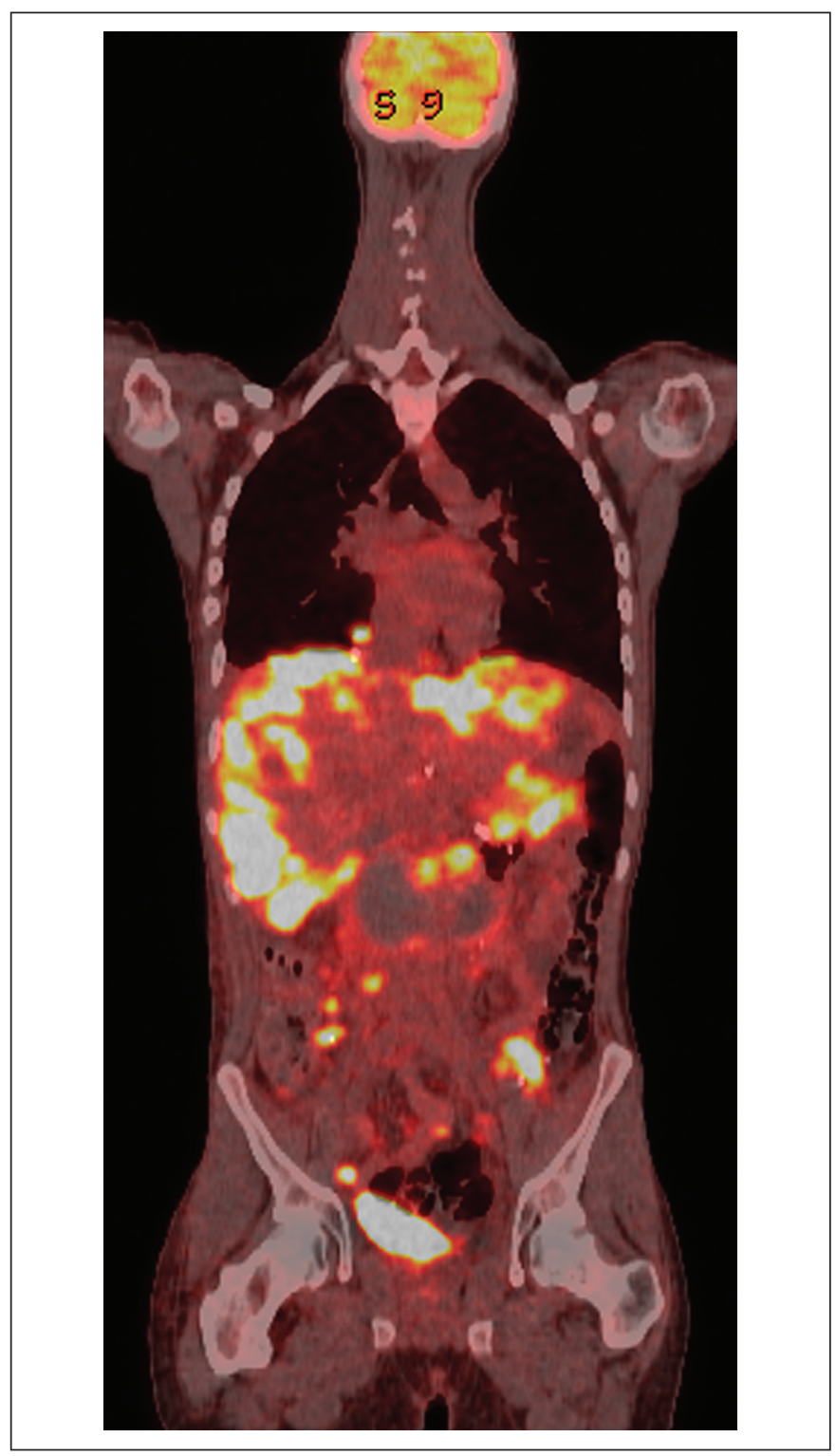

Fig 1.

there was progression of $\left[{ }^{18} \mathrm{~F}\right] \mathrm{FDG}$-avid bilobar hepatic metastases and multiple intra-abdominal implants.

Because the extensive hepatic parenchymal metastases remained untreated, therapy via the hepatic artery using $\left[{ }^{90} \mathrm{Y}\right]$ yttrium resin radioactive microspheres (SIR-Spheres; SIRTEX Medical, Sydney, Australia) ${ }^{1}$ was considered to encompass the disease-bearing portion of the liver because the porta hepatis tumor was radiation sensitive. A decision was made to use $\left[{ }^{90} \mathrm{Y}\right]$ yttrium resin radioactive microspheres. Delivery of $57.2 \mathrm{mCi}$ to the right and left hepatic arteries improved his nutritional and performance status. Metabolic response of multiple 


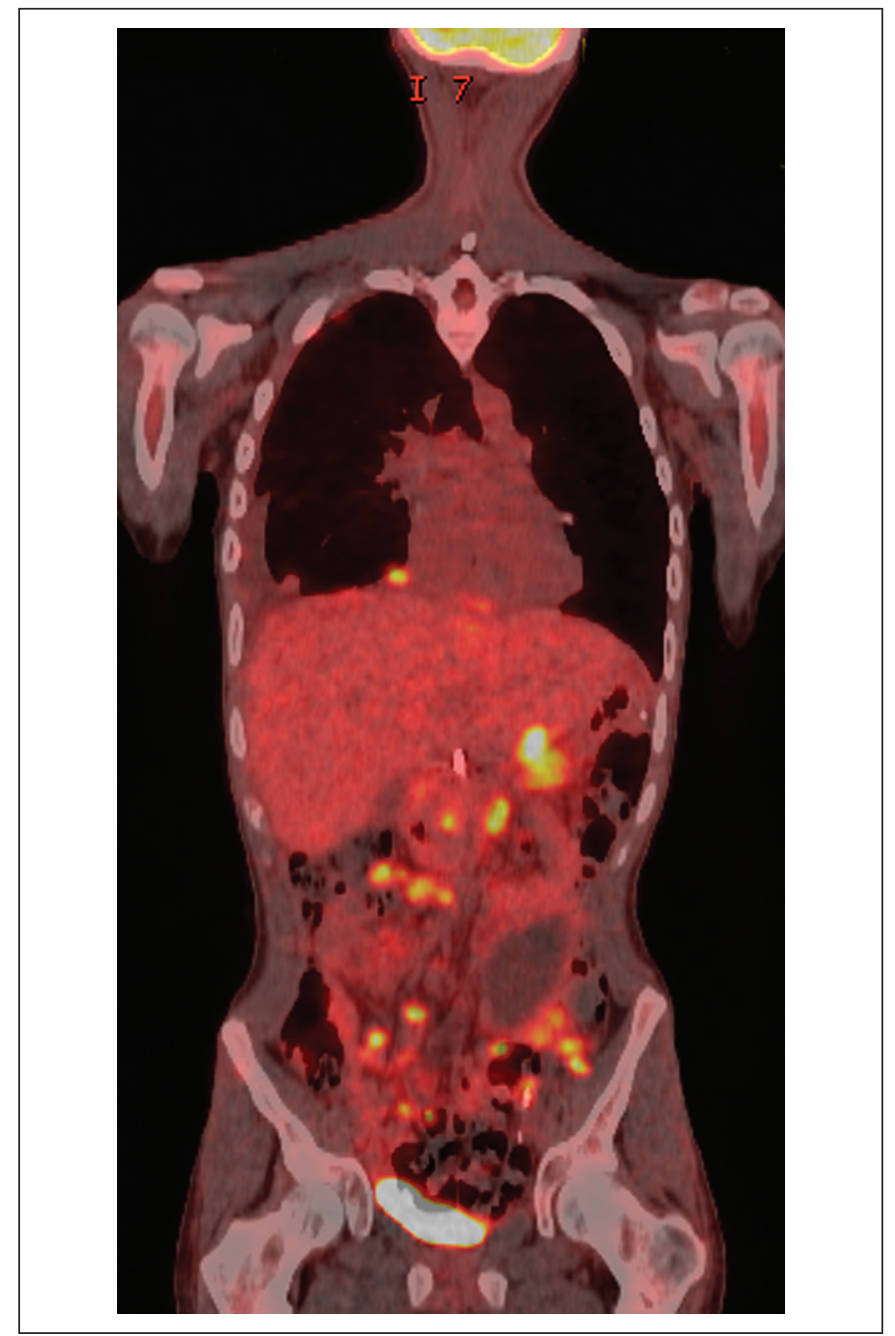

Fig 2.

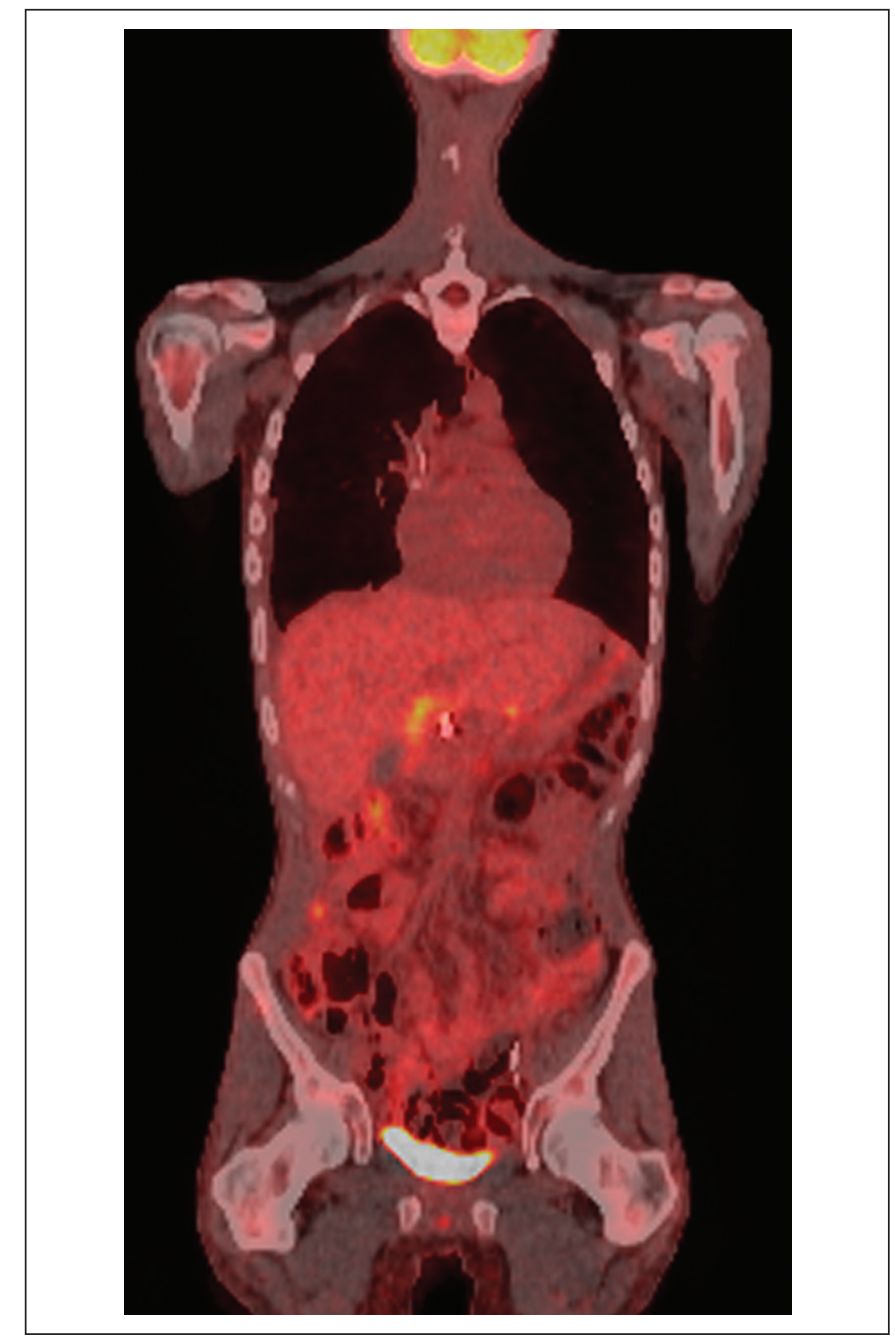

Fig 3. hepatic metastases to $\left[{ }^{90} \mathrm{Y}\right]$ yttrium resin radioactive microspheres therapy was seen (Fig 2).

After 1 month, the patient received pegylated interferon $(50 \mathrm{mcg}$ per week) for 3 months. $\left[{ }^{18} \mathrm{~F}\right]$ FDG PET-CT demonstrated progression in areas outside the radiotherapy field. He received $30 \mathrm{~Gy}$ of radiation to the sternum and L3-L5 region in 103-Gy fractions, along with chemotherapy consisting of gemcitabine and docetaxel. The patient had excellent response to radiotherapy, with no additional metabolically avid hepatic metastases and regression of $\left[{ }^{18} \mathrm{~F}\right] \mathrm{FDG}$-avid disease in retroperitoneal and intraperitoneal distributions. Seven months after the radioembolotherapy procedure, the patient continues to receive liposomal doxorubicin, and a follow-up PET-CT scan showed minimal liver disease (Fig 3).

\section{Discussion}

DSRCT is a disease occurring mainly in adolescent and young adult males, usually presenting with diffuse peritoneal sarcomatosis. ${ }^{2-4}$ DSRCT is distinguished from other small round blue cell tumors by the presence of the $t(11 ; 22)(p 13: q 12)$ chromosomal translocation. ${ }^{5}$ This translocation leads to fusion of the EWS gene (ie,
Ewing's sarcoma gene) to the tumor suppressor gene WT1 (ie, Wilms tumor 1 gene). ${ }^{6}$ The resultant chimeric protein acts as an aberrant transcription factor driving tumor proliferation. Despite demonstrated chemosensitivity with use of agents active against Ewing's sarcoma, optimal therapy for this rare disease remains to be defined.

Prognosis for patients with DSRCT is currently extremely poor. ${ }^{7}$ Usually, the disease is treated with an aggressive multimodality approach including high-dose multiagent chemotherapy (vincristine, doxorubicin, cyclophosphamide, ifosfamide/mesna, and etoposide), surgery, and conformal external beam radiation. ${ }^{8}$ Although DSRCT is responsive to Ewing's sarcoma-like alkylator-based chemotherapy, attaining durable remissions remains elusive. ${ }^{9}$ High-dose chemotherapy followed by autologous hematopoietic stem-cell rescue has not been associated with improved outcomes. ${ }^{9,10}$ Unresectable diffuse liver metastasis not amenable to surgery is uniformly fatal. However, novel treatment options such as CHPP may have a limited role in a few selected patients. ${ }^{11,12}$ Furthermore, radiotherapy seems to play a role in extending survival. ${ }^{13}$ Overall sensitivity and specificity with $\left[{ }^{18} \mathrm{~F}\right]$ FDG PET-CT have been reported superior to those with PET or CT alone in response to therapy in patients with DSRCT. ${ }^{14}$ 
Since approval by the US Food and Drug Administration in 2002 for the treatment of colorectal metastases in conjunction with intrahepatic fluorodeoxyuridine, $\left[{ }^{90} \mathrm{Y}\right] \mathrm{yttrium}$ resin microspheres have been tested in clinical trials for unresectable metastatic colorectal cancer. $\left[{ }^{90} \mathrm{Y}\right]$ yttrium, a high-energy beta emitter, is used as the radiotherapeutic agent delivered by microspheres for radioembolization, a means of administering internal radiotherapy to unresectable hepatic neoplasia. ${ }^{16}$ Unlike surgical resection or external radiation therapy, radioembolization is not limited by diffuse disease. ${ }^{1,17}$

In our patient, disease continued to progress through all reasonable cytotoxic therapy. After first-line therapy was completed, commercially available accepted second-line agents for refractory sarcomas-such as temozolimide plus irinotecan or cyclophosphamide plus vinorelbine-followed by CHPP were administered as outpatient chemotherapy. ${ }^{12,18}$ The patient also received insulinlike growth factor-1 receptor-based therapy, which is active in Ewing's sarcoma, ${ }^{19}$ because activation of the pathway in DSRCT is similar to that in Ewing's sarcoma. ${ }^{20}$ Treatment with $\left[{ }^{90} \mathrm{Y}\right] \mathrm{yttrium}$ radioembolotherapy led to a dramatic sustained reduction in the hepatic metastatic load in this aggressive cancer. In addition to controlling liver metastases, $\left[{ }^{90} \mathrm{Y}\right]$ yttrium microspheres improved quality of life in our young adult patient. He underwent and responded favorably to additional radiotherapy with gemcitabine and docetaxel as radiosensitizing chemotherapy. ${ }^{21}$

In summary, radioembolization with use of $\left[{ }^{90} \mathrm{Y}\right] \mathrm{yttrium}$ microspheres resulted in radiologic and clinical response against DSRCT. Given the poor prognosis in DSRCT, extension of survival by arresting the progression of metastatic cancer to the liver with use of radioembolotherapy is an approach to consider in selected patients with extensive liver DSRCT metastases.

\section{Vivek Subbiah, Ravi Murthy, and Pete M. Anderson}

The University of Texas MD Anderson Cancer Center, Houston, TX

\section{AUTHORS' DISCLOSURES OF POTENTIAL CONFLICTS OF INTEREST} Although all authors completed the disclosure declaration, the following author(s) indicated a financial or other interest that is relevant to the subject matter under consideration in this article. Certain relationships marked with a " $U$ " are those for which no compensation was received; those relationships marked with a "C" were compensated. For a detailed description of the disclosure categories, or for more information about ASCO's conflict of interest policy, please refer to the Author Disclosure Declaration and the Disclosures of Potential Conflicts of Interest section in Information for Contributors.

Employment or Leadership Position: None Consultant or Advisory Role: None Stock Ownership: None Honoraria: Ravi Murthy, Sirtex Medical Research Funding: None Expert Testimony: None Other Remuneration: None

\section{REFERENCES}

1. Murthy R, Nunez R, Szklaruk J, et al: Yttrium-90 microsphere therapy for hepatic malignancy: Devices, indications, technical considerations, and potential complications. Radiographics 25:S41-S55, 2005 (suppl 1)
2. Gerald WL, Rosai J: Case 2: Desmoplastic small cell tumor with divergent differentiation. Pediatr Pathol 9:177-183, 1989

3. Gerald WL, Miller HK, Battifora $\mathrm{H}$, et al: Intra-abdominal desmoplastic small round-cell tumor: Report of 19 cases of a distinctive type of high-grade polyphenotypic malignancy affecting young individuals. Am J Surg Pathol 15:499-513, 1991

4. Ordóñez NG, Zirkin R, Bloom RE: Malignant small-cell epithelial tumor of the peritoneum coexpressing mesenchymal-type intermediate filaments. Am J Surg Pathol 13:413-421, 1989

5. Rodriguez E, Sreekantaiah C, Gerald W, et al: A recurring translocation, $\mathrm{t}(11 ; 22)(\mathrm{p} 13 ; \mathrm{q} 11.2)$, characterizes intra-abdominal desmoplastic small round-cell tumors. Cancer Genet Cytogenet 69:17-21, 1993

6. Benjamin LE, Fredericks WJ, Barr FG, et al: Fusion of the EWS1 and WT1 genes as a result of the $t(11 ; 22)(p 13 ; q 12)$ translocation in desmoplastic small round cell tumors. Med Pediatr Oncol 27:434-439, 1996

7. Stuart-Buttle CE, Smart CJ, Pritchard S, et al: Desmoplastic small round cell tumour: A review of literature and treatment options. Surg Oncol 17:107-112, 2008

8. Kushner BH, LaQuaglia MP, Wollner N, et al: Desmoplastic small roundcell tumor: Prolonged progression-free survival with aggressive multimodality therapy. J Clin Oncol 14:1526-1531, 1996

9. Lal DR, Su WT, Wolden SL, et al: Results of multimodal treatment for desmoplastic small round cell tumors. J Pediatr Surg 40:251-255, 2005

10. Saab R, Khoury JD, Krasin M, et al: Desmoplastic small round cell tumor in childhood: The St Jude Children's Research Hospital experience. Pediatr Blood Cancer 49:274-279, 2007

11. Hayes-Jordan A, Green H, Fitzgerald N, et al: Novel treatment for desmoplastic small round cell tumor: Hyperthermic intraperitoneal perfusion. J Pediatr Surg 45:1000-1006, 2010

12. Aguilera $D$, Hayes-Jordan $A$, Anderson $P$, et al: Outpatient and home chemotherapy with novel local control strategies in desmoplastic small round cell tumor. Sarcoma 2008:261589, 2008

13. Subbiah V, Anderson PM, Hayes-Jordan A, et al: Desmoplastic small round cell tumor: Evolving treatment options. Presented at the 15th Annual Meeting of the Connective Tissue Oncology Society, Miami, FL, November $5-7,2009$

14. Kushner $\mathrm{BH}$, Laquaglia MP, Gerald $\mathrm{WL}$, et al: Solitary relapse of desmoplastic small round cell tumor detected by positron emission tomography/ computed tomography. J Clin Oncol 26:4995-4996, 2008

15. Reference deleted

16. Nicolay NH, Berry DP, Sharma RA: Liver metastases from colorectal cancer: Radioembolization with systemic therapy. Nat Rev Clin Oncol 6:687-697, 2009

17. Salem R, Lewandowski RJ, Sato $K T$, et al: Technical aspects of radioembolization with 90Y microspheres. Tech Vasc Interv Radiol 10:12-29, 2007

18. Ferrari $A$, Grosso F, Stacchiotti $S$, et al: Response to vinorelbine and low-dose cyclophosphamide chemotherapy in two patients with desmoplastic small round cell tumor. Pediatr Blood Cancer 49:864-866, 2007

19. Subbiah V, Anderson P, Lazar AJ, et al: Ewing's sarcoma: Standard and experimental treatment options. Curr Treat Options Oncol 10:126-140, 2009

20. Werner $H$, Idelman $G$, Rubinstein $M$, et al: A novel EWS-WT1 gene fusion product in desmoplastic small round cell tumor is a potent transactivator of the insulin-like growth factor-I receptor (IGF-IR) gene. Cancer Lett 247:84-90, 2007

21. Anderson $P$, Aguilera $D$, Pearson $M$, et al: Outpatient chemotherapy plus radiotherapy in sarcomas: Improving cancer control with radiosensitizing agents. Cancer Control 15:38-46, 2008

DOI: $10.1200 / J C O .2010 .32 .4673$; published online ahead of print at www.jco.org on January 18, 2011

\section{Acknowledgment}

Supported in part by the National Institutes of Health through MD Anderson Cancer Center Support Grant No. CA016672. 